\title{
Inflation, Growth and Real and Nominal Uncertainty: Some Bivariate Garch-in-Mean Evidence for Brazil*
}

\author{
Sergio Rodrigo Vale ${ }^{* *}$
}

Summary: 1. Introduction; 2. Econometric methodology; 3. Data; 4. Empirical results; 5. Conclusion.

Keywords: Inflation; growth; uncertainty; bivariate GARCH-inmean.

JEL codes: C32; E20; E31.

In this paper I intend to estimate a bivariate GARCH-in-Mean in order to test four hypotheses about Brazilian economy. First, I want to know whether inflation uncertainty has a positive impact on the level of inflation as predicted by Cukierman and Meltzer (1986). Second, I want to test if this uncertainty has a negative impact on growth as proposed by Friedman (1977). Third, it will be tested the hypothesis of a negative impact of uncertainty growth on the level of growth as pointed out by Ramey and Ramey (1991). Finally, I will test if this uncertainty has a positive impact on the level of inflation as predicted by Deveraux (1989). The findings are a little mixed but in all settings they corroborate Cukierman and Meltzer explanation and some of them corroborate Friedman's theory.

O objetivo deste artigo e estimar um GARCH-in-Mean bivariado para testar quatro hipóteses sobre a economia brasileira. Primeiro, quero testar se a incerteza inflacionaria tem um impacto positivo no nível de inflacão como previsto por Cukierman and Meltzer (1986). Segundo, testo se esta incerteza tem um impacto negativo no crescimento como proposto por Friedman (1977). Terceiro, será testada a hipótese de um impacto negativo da incerteza no crescimento sobre o nível de crescimento como apontado por Ramey and Ramey (1991). Finalmente, testarei se esta incerteza tem um impacto positivo no nível de inflação como previsto por Deveraux (1989). Os resultados são variados, mas em todos os modelos estimados corrobora-se a hipótese de Cukierman e Meltzer e em alguns se corrobora a hipótese de Friedman.

\footnotetext{
${ }^{*}$ This paper was received in Aug. 2002 and approved in Aug. 2004. I would like to thank Kenneth West and an anonymous referee for useful remarks and $\mathrm{CNPq}$ for the financial support. All remaining errors are my sole responsibility.

${ }^{* *}$ MB Associados e Ibmec, São Paulo. E-mail: sergiorv@ibmec.br
} 


\section{Introduction}

The relationship between inflation and growth has become an intense research branch since the Mundell-Tobin effect was first described. In this earlier formulation the connection between economic growth and inflation comes out from a framework that has only two assets: money and capital. In steady state an increase in the rate of return of money implies a decrease in return of the other asset (they are assumed to be substitutes in the household portfolios). In other words, an increase in inflation positively impacts capital accumulation and consequently growth. ${ }^{1}$ But this result has systematically been challenged in empirical and theoretical papers. For instance, Jones and Manuelli (1995) and De Gregorio (1993) points out that inflation is a tax on capital in models with cash-in-advance requirement for investment and, as a consequence, impacts growth negatively. Similarly, most of empirical papers has shown a negative relationship between these two variables but without a theoretical agreement about the reasons for the negative relation. ${ }^{2}$ But in economies with high uncertainty in growth and inflation the simple relationship between those two variables may be unsatisfactory.

With this explanation gap in mind, Friedman's Nobel lecture pointed out another type of interference on growth. His argument hinges on two mechanisms. First, changes in the optimal wage contract length and the degree of wage indexation caused by inflation uncertainty could increase unemployment and, by some sort of Okun's Law, decrease growth. Second, increased volatility in inflation causes a less efficient system for coordinating economic activity. Based in arguments stemmed from Hayek (1945) and Lucas (1973), he argues that stable prices and stable price changes ease the signal extraction of relative prices from the observed absolute prices. Thus, when general inflation is more uncertain it is more difficult to extract relative prices from absolute prices. At the end of the process, absolute prices become innocuous and the agents resort to an alternative currency or to barter. This was the Brazilian case between mid-eighties and mid-nineties when we went through a hyperinflation process and currency lost practically all its value. ${ }^{3}$

\footnotetext{
${ }^{1}$ See Walsh (1998) for a survey of the models used to explain this relation.

${ }^{2}$ For instance, Bruno and Easterday (1998) show that high inflation economies are more susceptible to find negative relations between growth and inflation but that in cross-section analysis this relation seems to be ambiguous or even inexistent. The reason is that rapid and huge increases and decreases in inflation has a boom effect on growth which is not captured in mild inflationary processes. However, Barro (1996) uses another data set and find a negative crosssection relation between the two variables in fairly general contexts using arguments similar to Jones and Manuelli (1995).

${ }^{3}$ In a recent paper, Dotsey and Sarte (2000) argue that in the long run inflation uncertainty
} 
Cukierman and Meltzer (1986) claim that increases in inflation uncertainty raise the optimal average inflation rate by increasing the incentive for the policymaker to create inflation surprises. In their model Central Bank dislikes inflation but likes to stimulate economy. Ambiguity and lack of commitment over policies induce a higher variance of monetary growth and a higher variance in employment but agents cannot distinguish where this variance comes from. As a consequence the ambiguity allows the Central Bank to create inflation surprises. ${ }^{4}$ This seems also to be the case in Brazil where a Central Bank managed by the political convenience of the moment prevented it to have a clear monetary policy.

Deveraux (1989) extended Barro and Gordon (1983) model to show that variability in real shocks can positively affect inflation. The reason is that an exogenous increase in the growth uncertainty lowers the optimal quantity of wage indexation. From the point of view of the policymaker a lower indexation can make surprise inflation more effective and, as a result, increase the average inflation rate. Therefore, Devereux concludes that output growth uncertainty can increase inflation.

Finally, Ramey and Ramey (1991) suppose a simple general equilibrium model in which firms make technology commitments in advance, e.g., the determination of the scale of a new factory or the size of the attached labor force. Each technology corresponds to a different minimum efficient scale and in the absence of economic fluctuations firms would choose their technology to bring minimum efficient scale into line with the equilibrium output level. However, if growth volatility (higher economic instability) increases, equilibrium output levels may depart from minimum efficient scale and firms may end up with average costs above the minimum level. Thus, volatility causes firms' production plans to be sub optimal ex-post and as a consequence growth uncertainty diminishes the average real growth.

What these apparently unrelated arguments have in common is the systematic connection between uncertainty measures (in growth and inflation) and the respective level measures. To estimate these relations simultaneously I will apply

adversely affects long run growth but the effect can be quite the contrary in the short run. The reason for this positive relationship in the short term stems from a precautionary savings motive. But Issler et al. (1998) show that precautionary savings in Brazil is not significant.

${ }^{4}$ Ball (1992) proposes an inverse relationship. In his paper the causality runs from high inflation to high inflation uncertainty. He argues that when actual and expected inflation are low it is also expected that the monetary authority will try to keep them low. But when inflation is high policymakers face a dilemma. Indeed, in this case the Central bank would like to disinflate, but fear the possible recession that would result. The agents do not know the tastes of future policymakers and thus does not know when the disinflation will occur. As a consequence, inflation uncertainty may rise. 
a bivariate GARCH-M model using output growth and inflation as the dependent variables in the mean equation. The right hand side will contain variables that help to forecast growth and inflation and the uncertainty measures, which are calculated from the equations errors.

Specifically, I intend to test four hypotheses for Brazilian economy. First, I want to know whether inflation uncertainty adversely impacts real growth, as predicted by Friedman; second, whether inflation uncertainty positively impacts inflation rate as pointed by Cukierman and Meltzer; third, whether growth uncertainty raises average inflation as shown in Devereux's model and, fourth, whether a more volatile growth promotes a lower average growth, as proposed by Ramey and Ramey.

The paper will be divided in five parts. Besides this introduction, the second part will quickly describe the bivariate GARCH methodology I will use. The third section will present the data used in this work. The fourth part will show the estimations made and, finally, the last part will conclude.

\section{Econometric Methodology}

We want to calculate the impact of uncertainty variables on level variables. The best way to do this is applying a bivariate GARCH-M model that has the following specification

$$
\begin{gathered}
\pi_{t}=\alpha_{0}+\alpha_{1} x_{t}+\beta_{1} \sigma_{s}^{2}+\beta_{2} \sigma_{v}^{2}+\epsilon_{t} \\
y_{t}=\alpha_{2}+\alpha_{3} z_{t}+\beta_{3} \sigma_{s}^{2}+\beta_{4} \sigma_{v}^{2}+v_{t} \\
H_{t}=C^{\prime} C+\sum_{k=1}^{K} \sum_{i=1}^{q} A_{i k}^{\prime} \eta_{t-1} \eta_{t-1}^{\prime} A_{i k}+\sum_{k=1}^{K} \sum_{i=1}^{p} G_{i k} H_{t-i} G_{i k}
\end{gathered}
$$

where $t$ is the inflation rate, $y_{t}$ is the growth rate, $x_{t}$ and $z_{t}$ are explanatory variables that help to forecast inflation and growth, $\sigma_{\epsilon}^{2}$ and $\sigma_{v}^{2}$ are the conditional variance of the error in the first and second equations, respectively. The third equation shows the variance-covariance process where $C, A_{i k}$ and $G_{i k}$ are $n \times n$ parameter matrices with $C$ triangular. $K$ determines the generality of the process.

This specification is called BEKK model and is due to Engle and Kroner (1995). Its improvement upon other models of this class is that the representation for the $H_{t}$ matrix guarantees it is positive definite for all values of $t$ and, additionally, 
we have less parameters to estimate compared to traditional Vec representations. ${ }^{5}$ This model also has a difference with traditional models because we add uncertainty measures in the mean equations. This representation stems from Bollerslev et al. (1988) but they calculate their model using a Vec representation. To avoid too many parameters to estimate we will suppose a GARCH-M $(1,1)$ formulation where $H_{t}$ is given by:

$$
\begin{aligned}
H_{t}=C^{\prime} C+ & {\left[\begin{array}{ll}
a_{11} & a_{12} \\
a_{21} & a_{22}
\end{array}\right]^{\prime}\left[\begin{array}{cc}
\epsilon_{t-1}^{2} & \epsilon_{t-1} v_{t-1} \\
v_{t-1} \epsilon_{t-1} & v_{t-1}^{2}
\end{array}\right]\left[\begin{array}{ll}
a_{11} & a_{12} \\
a_{21} & a_{22}
\end{array}\right] } \\
& {\left[\begin{array}{ll}
g_{11} & g_{12} \\
g_{21} & g_{22}
\end{array}\right]^{\prime} H_{t-1}\left[\begin{array}{ll}
g_{11} & g_{12} \\
g_{21} & g_{22}
\end{array}\right] }
\end{aligned}
$$

Following the suggestions made by Grier and Perry (2000)'s paper, I will first estimate single equations by OLS for equations (1) and (2) without the uncertainty measures. With this I will test for equations (1) and (2) the presence of ARCH terms by a Ljung-Box test. The estimation method will be by quasi-maximum likelihood proposed by Bollerslev and Wooldridge (1992). Their estimator is consistent for nonnormality of the residuals, which is a common feature of this kind of model. ${ }^{6}$ Finally, the estimation of (1), (2) and (4) will follow the numerical optimization algorithm proposed by Berndt et al. (1974) and known as BHHH.

\section{Data}

I am using monthly Brazilian data to estimate the model. The series are seasonally adjusted industrial production ${ }^{7}$ and PPI both calculated by IBGE (Brazilian Institute of Geography and Statistics). Additionally, I will use CPI provided by FIPE (Institute of Economic Research Foundation). ${ }^{8}$ The reason to use a different source is that the CPI calculated by IBGE only started to run in 1979 and I intend to use a longer series. Moreover, PPI is not calculated by FIPE. For the inflation series we have $t=\log \left(P_{t} / P_{t-1}\right) * 100$ where $P_{t}$ is the price index for each series and growth is given by $y_{t}=\log \left(I P t / I P_{t-1}\right) * 100$ where $I_{P} t$ is the industrial production index. In the growth equation I also use a default risk measure given by the

\footnotetext{
${ }^{5}$ See Bollerslev et al. (1994) and Engle and Kroner (1995) for more details.

${ }^{6}$ Grier and Perry's paper uses the traditional maximum likelihood estimation for US data but does not care about the nonnormality of the residuals.

${ }^{7}$ The reason for using industrial production instead of a general measure of GNP is that this monthly data is only available from 1991 on.

${ }^{8}$ Alternative estimations using CPI calculated by FGV (IGP-DI) delivered similar results and is available upon request.
} 
difference between the working capital interest rate and the overnight interest rate. The first series is a lending rate (Capital de Giro) and the second is a series that represents the most traded Treasury Note at the moment. ${ }^{9}$ The available range is from January 1975, when the industrial production index was first measured, to December 2001. We could estimate the same model using yearly data but the problem is that the range is too short to give accurate results since we depend on asymptotic results provided by the quasi-maximum likelihood estimation. ${ }^{10}$ The series used in this work are depicted in figures 1 and 2 .

Figure 1

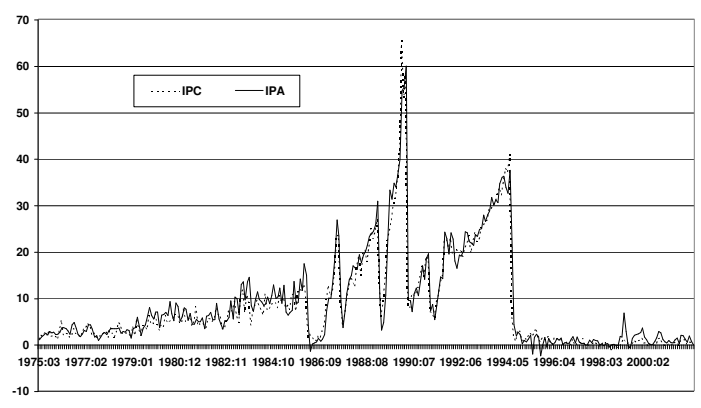

Figure 2

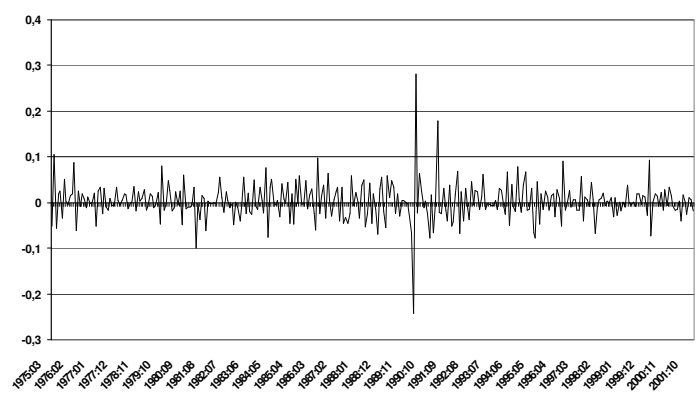

\footnotetext{
${ }^{9}$ This occurs because some securities were changed due to changes of government or due to a stabilization plan that launched a different Treasury Note. See Cenarios (no date) for more details.

${ }^{10}$ Nonnormality of residuals also was detected in a preliminary estimation of the model with yearly data, which indicates the necessity of applying quasi-maximum likelihood methods.
} 


\section{Empirical Results}

\subsection{Unit root tests for inflation and growth}

The natural result when we test for unit root in growth and inflation is to find a stationary process for both series. In fact, when we apply the traditional $\mathrm{ADF}$ and PP (Philips-Perron) unit root tests we get two stationary series as a result. However, Perron et al. (1999) showed that this is not the case for the Brazilian inflation, where we had six stabilization plans in less than ten years. This occurs because 'we can view the stabilization plans as creating 'inliers' whose magnitude is related to the current level of the series. Hence, if the series truly has a stochastic trend or even an explosive path, the magnitude of these inliers are, themselves, non-stationary random variables that have a tendency to increase as inflation increases. Since these shocks plans have failed, the series exhibits a tendency to return to its old (non-stationary) trend path after each episode. This is basically what contaminates the standard statistical measures, since the failures of the shock plans create a kind of spurious mean-reverting aspect to the series' (Perron et al. (1999, p.28)). The data they used to test for unit root ended in June, 1993, months before the last stabilization plan (Real Plan) and the only one that knocked inflation down permanently. Thus, besides the inliers dummies for the flawed plans we have to add permanent break dummies due to the stabilization plan that worked (the Real Plan). ${ }^{11}$ The formulation for the ADF test based on the 'innovational outlier' framework presented in their paper is given by:

$$
\begin{aligned}
y_{t} & =\mu+\gamma t+\sum_{j=1}^{p}\left(k_{j} d a(j)_{t}+\lambda_{j} d b(j)_{t}+\phi_{j} D(j)_{t}\right)+\theta_{1} D U_{t}+\theta_{2} D U_{t} \\
& +\theta_{3} D(T B)_{t}+\alpha y_{t-1}+\sum_{i=1}^{k} c_{i} \Delta y_{t-i}+\zeta_{t}
\end{aligned}
$$

where $j$ correspond to each one of the five stabilization plans; $d a(j)=1$ in the first month of the plan and 0 otherwise (pulse dummy); $d b(j)=1$ for the first

\footnotetext{
${ }^{11}$ According to Perron in a previous change of e-mails this addition does not change the results they obtained in their papers because we can treat the Real Plan as a permanent break. Thus, the only difference from their paper is that we must use the critical values reported in Perron (1989). Note additionally that we are treating the break as known because we indeed know when the Plan was implemented. Anyway, a model of endogenous break based on Perron and Vogelsang (1994) also was estimated and delivered the same results. To learn more about each stabilization plan see Pio (2000).
} 
month after the end of the plan and 0 otherwise (pulse dummy); $D(j)=1$ during the plan and 0 otherwise ${ }^{12}$ (level dummy). Additionally, we add three dummies related to the Real Plan: $D U_{t}=1$ if $t>T_{B}$ and 0 otherwise; $D T_{t}=t$ it $t>T B$ and 0 otherwise and $D(T B) t=1$ if $t=T B+1$ and 0 otherwise. This equation is a mix of the equation (14) in Perron's (1989) paper and equation (15) in Perron et al.'s (1999) paper.

An additive outlier model can also be formulated and it has the following expression:

$$
y_{t}=\mu+\gamma t+\sum_{i=0}^{k+1} \sum_{j=1}^{p} \phi_{j, i} D(j)_{t-i}+\theta D T_{t}+\varphi D L_{t}+\alpha y_{t-1}+\sum_{i=1}^{k} c_{i} \Delta y_{t-i}+\zeta_{t}
$$

The results in table 1 and 2 are a little mixed with the innovational outlier model pointing to no unit root for PPI. But I will stick with the additive outlier model because the change in inflation process was abrupt and not gradual as supposed by the innovational outlier model. Moreover, the GARCH-M estimated without differencing PPI never presented invertible AR terms and delivered poor results. Thus, I will accept the null hypothesis of one unit root for both series.

Finally, the traditional ADF unit root test performed for the growth rate pointed out an ADF statistic of -10.52, which means that growth rate is stationary at $1 \%$. The same statistic for the default risk measure is -5.47 and it also means that this variable is stationary at $1 \%$.

With these results the GARCH system will have a mean equation for the growth level and a mean equation for the first difference of the inflation rate. This is not really unconformable with our theories because they suppose that not only inflation rate can have the desired impacts we want but the growth rate of inflation too. 13

\footnotetext{
${ }^{12}$ Perron and Vogelsang (1994) discuss the exact period of each plan and presents a table with the duration of each plan.

${ }^{13}$ See particularly the discussion in Friedman (1977). In fact, he puts more influence of the uncertainty in the growth rate of inflation on this one than the uncertainty in the rate of inflation on this one.
} 
Table 1

Unit Root Test (ADF-Perron-Cati-Garcia innovational outlier model)

\begin{tabular}{|c|c|c|c|}
\hline Series & $t$-statistic & $\hat{\alpha}$ & gs \\
\hline SPI & -3.5 & .861 & 1 \\
\hline PI & -6. & .763 & 1 \\
\hline \multicolumn{4}{|c|}{$\begin{array}{l}\text { Note: The decision rule was based } \\
\text { on BIC criterion and the general-to- } \\
\text { specific rule. Additionally, Ljung-Box } \\
\text { tests were performed in the residuals } \\
\text { and all showed white noise. ** de- } \\
\text { notes one unit root at } 5 \% \text {. The critical } \\
\text { value is based on Perron (1989) and de- } \\
\text { pends on the break date. In our case } \\
\text { we have to divide the number of ob- } \\
\text { servations until the break divided by } \\
\text { the total number of observations. This } \\
\text { gives } \lambda=245 / 322 \approx 0.8 \text { and using ta- } \\
\text { ble VI.B in Perron for this value we get } \\
\text { a critical value of }-4.04 \text { at } 5 \% \text {. }\end{array}$} \\
\hline
\end{tabular}

Table 2

Unit Root Test (ADF-Perron-Cati-Garcia additive outlier model)

\begin{tabular}{|c|c|}
\hline$t$-statistic & lags \\
\hline$-1.28^{* *}$ & 0.949 \\
\hline-3.88 & 0.864 \\
\hline $\begin{array}{l}\text { Note: The decision } \\
\text { on BIC criterion and } \\
\text { specific rule. Addition } \\
\text { tests were performed } \\
\text { and all showed white } \\
\text { notes one unit root at } \\
\text { value is based on Perro } \\
\text { pends on the break de } \\
\text { we have to divide the } \\
\text { servations until the b } \\
\text { the total number of ob } \\
\text { gives } \lambda=245 / 322 \approx 0 \\
\text { ble VI.B in Perron for } t\end{array}$ & $\begin{array}{l}\text { le was based } \\
\text { he general-to- } \\
\text { ly, Ljung-Box } \\
\text { the residuals } \\
\text { loise. ** de- } \\
\text { o. The critical } \\
\text { (1989) and de- } \\
\text { In our case } \\
\text { amber of ob- } \\
\text { ak divided by } \\
\text { andions. This } \\
\text { is value we get }\end{array}$ \\
\hline
\end{tabular}

\subsection{OLS models for inflation and growth}

As written before I will estimate single-equation OLS models before starting the system analysis. The objective is twofold. First, the results in the single mean equations can support or not the hypothesis of nonnormality of residuals and this 
is fundamental for choosing the method of estimation. Second, the estimation of the single equations allows preliminary diagnose tests on the residuals in order to detect the presence of GARCH terms.

The results show the existence of correlation in the squared residuals in all equations, which is a signal of the presence of $\mathrm{ARCH}$ terms. Clearly, this does not mean that the existence of $\mathrm{ARCH}$ terms is guaranteed in the bivariate system but it will turn out to be true when I estimate the system. Note that we added dummies to each equation. These dummies have value 1 at the moment of the stabilization plan and zero otherwise and are named after the definition given before. The inclusion of these dummies occurs because when the inflation series are differentiated they show negative spikes due to the implementation of each stabilization plan as is shown in figure 3. Without the dummies the inflation equations presented pour results in terms of Schwartz criterion (SIC) and LjungBox test. ${ }^{14}$ Moreover, these dummies eliminate the spurious increase in volatility caused by the immediate afterwards of each economic plan.

It is interesting to note that the inclusion of the default risk rate turned out to be insignificant in the growth equation as well in the bivariate GARCH and thus will not be considered in the estimations. Note also that the Jarque-Bera test points out to the nonnormality of the residuals, which indeed indicate the necessity of using quasi-maximum likelihood methods.

An alternative modeling was tried. We estimated a VAR to capture bivariate relations between the growth and inflation mean equations. ${ }^{15}$ Using a sequential modified LR test and SIC criterions a VAR (3) was chosen using $\mathrm{CPI}^{16}$ However, in this case many of the estimated parameters were not significant and the multivariate statistical tests were quite poor ${ }^{17}$ Similar results were found for PPI for

\footnotetext{
${ }^{14}$ It is necessary to note that we used SIC as the decision criterion for the most parsimonious model throughout the paper. A multivariate version of SIC is used for the bivariate GARCH and it is detailed on the next section.

${ }^{15}$ It is well known that even if there are MA components in the system we can approximate a VARMA by a VAR with a reasonable number of lags.

${ }^{16}$ The sequential modified LR tests as proposed by Lutkepohl (1991) is given by $L R=$ $(T-m)\left\{\log \left|\Omega_{l-1}\right|-\log \left|\Omega_{l}\right|\right\}-\chi^{2}\left(K^{2}\right)$ where $m$ is the number of parameters to be estimated in each equation and $(T-m)$ is a small sample modification proposed by Sims (1980). Here we test that the coefficients on lag 1 are jointly zero using the 2 statistic. It is worthwhile to say that Atkins (AIC) and Hannan-Quinn (HQ) criterions also pointed 3 lags as the best model.

${ }^{17}$ For instance, a multivariate LM test such as the one proposed by Johansen (1995) points out the presence ou autocorrelation for all lags of the VAR. As it happens, for lag 4 the LM test presents a statistic of 2.04 and a p-value of 0.72 using a 2 with 4 degrees of freedom. However, a multivariate White heteroskedasticity test was applied and detected the presence of heteroskedasticity at 5\% using again a 2 and getting a joint test of 228.8. See Doornik (1996) ant the next section for details ofon this test. Additionally, a joint Jarque-Bera test was also applied and
} 
which a VAR (3) was also identified. But since this is a preliminary view with the sole intention of identifying the presence of heteroskedasticity we must rely on our bivariate GARCH estimation to analyze if there is conditional volatility or not.

\section{Table 3}

OLS regressions for inflation and growth - 1975:03 to 2001:12

$\frac{\text { A: Growth }}{y_{t}=\underset{(0.0001)}{0.0001}-\underset{(0.05)}{0.32} y_{t-1}-\underset{(0.05)}{0.10} \epsilon_{t-3}+\underset{(0.05)}{0.16} \epsilon_{t-9}}$

Log likelihood function $=1331.4$

Ljung-Box $Q(4)=6.82(0.14)$

Ljung-Box $Q(12)=20.03(0.07)$

Ljung-Box $Q^{2}(4)=31.99(0.00)$

Ljung-Box $Q^{2}(12)=46.74(0.00)$

Jarque-Bera $=2946.7(0.00)$

\begin{tabular}{|c|}
\hline B: CPI \\
\hline$\pi_{t}=\underset{(3.09)}{9.06}+\underset{(0.06)}{0.25} \pi_{t-1}+\underset{(0.06)}{0.75} \pi_{t-3}-\underset{(0.05)}{0.16} \pi_{t-5}+\underset{(0.07)}{1.02} v_{t-1}$ \\
\hline$+\underset{(0.08)}{0.84} v_{t-2}-\underset{(0.06)}{0.28} v_{t-4}-\underset{(0.06)}{0.15} v_{t-5}+\underset{(0.04)}{0.11} v_{t-9}-\underset{(1.83)}{3.46} d a(1)$ \\
\hline$\underset{-(1.83)}{5.70} d a(2)-\underset{(1.86)}{3.63} d a(3)+\underset{(3.20)}{20.20 d a} d(4)+\underset{(1.95)}{5.24} d a(5)-\underset{(2.00)}{16.20 D} D(T B)$ \\
\hline Log likelihood function $=-773.6$ \\
\hline Ljung-Box $Q(4)=6.23(0.18)$ \\
\hline Ljung-Box $Q(12)=10.04(0.69)$ \\
\hline Ljung-Box $Q^{2}(4)=82.18(0.00)$ \\
\hline Ljung-Box $Q^{2}(12)=83.32(0.00)$ \\
\hline Jarque-Bera = $1894(0.00)$ \\
\hline C: PPI \\
\hline$\pi_{t}=\underset{(3.91)}{9.48}+\underset{(0.05)}{1.27} \pi_{t-1}-\underset{(0.09)}{0.48} \pi_{t-2}-\underset{(0.06)}{0.18} \pi_{t-3}-\underset{(0.06)}{0.20} v_{t-4}$ \\
\hline$-\underset{(0.06)}{0.20} v_{t-11}-\underset{(1.90)}{1.72} d a(1)-\underset{(1.89)}{2.29} d a(2)-\underset{(1.92)}{7.30} d a(3)$ \\
\hline$+\underset{(2.96)}{16.65 d a(4)}+\underset{(1.93)}{6.81} d a(5)-\underset{(1.93)}{1.21} D(T B)$ \\
\hline
\end{tabular}

Log likelihood function $=-789.8$

Ljung-Box $Q(4)=4.39(0.182)$

Ljung-Box $Q(12)=10.89$ (0.620)

Ljung-Box $Q^{2}(4)=59.40(0.000)$

Ljung-Box $Q^{2}(12)=80.64(0.000)$

Jarque-Bera $=201.3(0.00)$

Note: standard errors are in parentheses under the coefficients. $Q(4)$ and $Q(12)$ are the Ljung-Box statistics for fourth- and twelfth-order serial correlation in the residuals. $Q^{2}(2)$ and $Q^{2}(12)$ are the same statistics but it corresponds to the serial correlation in squared residuals. Jarque-Bera is the test for normality of residuals. The numbers in parentheses after these statistics are the p-value. BIC was also used as a criterion for decision. The dummies $d a_{(j)}$ and $D(T B)$ correspond to the definition given before. The first one has 1 at the moment of the stabilization plan and zero otherwise in the first five plans and $D(T B)$ is 1 for the moment of implementation of the Real Plan and zero otherwise.

statistic of 40935.9 was found which means nonnormality at $5 \%$. 
Figure 3

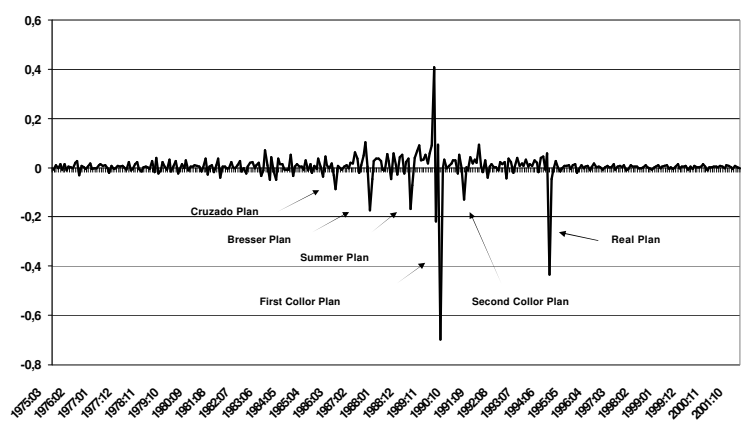

\subsection{Bivariate $\mathrm{GARCH}(1,1)-\mathrm{M}$ for inflation and growth and discus- sion}

The results presented in Tables 4 and 5 show that the estimated equations correct for the existence of GARCH terms in the residuals and this can be seen by the Ljung-Box test on the squared residuals. It is important to note that a multivariate SIC criterion was used to find the most parsimonious model and it is given by

$$
\left.S I C=\ln \left|\widehat{\sum}\right|+\frac{\ln n}{n} \text { (number of freely estimated parameters }\right)^{18}
$$

where $n$ is the number of observations and $\sum$ is the estimated variance-covariance matrix.

Additionally, a multivariate LM test for the residuals was performed. Following Doornik (1996) we test that $L M=T n R_{m}^{2}$ with a $\chi^{2}\left(s n^{2}\right)$ asymptotic distribution where $T$ is the number of observations, $n$ is the number of equations in the system and $R_{m}^{2}$ is given by

$$
R_{m}^{2}=1-\operatorname{tr}\left\{\left(\hat{V}^{\prime} \hat{V}\right)\left(V_{0}^{\prime} V_{0}\right)^{-1}\right\}
$$

\footnotetext{
${ }^{18}$ We considerer Hannan-Quinn criterion as an alternative but it did not change the results. For lag selection in asymmetric models see Ozcicek and McMillin (1999)
} 
where $V$ are the residuals of the regressions supposing the residuals are auto correlated and $V_{0}$ are the residuals under the null hypothesis of no autocorrelation.

Despite the L-B tests for the growth mean equations be a little disappointing it was the best specification found. Note that I used the conditional standard deviation instead of the variance in the mean equations because the system did not converge when I tried the conditional variance.

The variance-covariance estimates are formatted as presented in equation (4) and all coefficients are significant. When 0 appears instead of one of the coefficients it means that it was not significant and it was dropped of the equations.

In table 4, where I use CPI, the results show that two of the coefficients do not have the expected sign. In fact, only the inflation uncertainty measure $\left(\sigma_{v}\right)$ on the inflation equation and on the growth equation was significant and had the right sign. The growth uncertainty measure $\left(\sigma_{\epsilon}\right)$ presented the wrong sign and was not significant in both equations. This means that inflation uncertainty had a higher impact than growth uncertainty in this period on both variables. Indeed, inflation was the central economic problem throughout this period and economic agents had a major worry about the impacts of a huge and increasing inflation on growth and on inflation itself.

The results for PPI are a little different in terms of significance but present the same coefficients signs of CPI's results and similar magnitudes. Particularly, inflation uncertainty is still significant in the inflation equation but it is not in the growth equation. And now $\sigma_{\epsilon}$ has a significant and positive impact on the growth equation, which contradicts Ramey and Ramey theoretical findings. It should be natural to stick with the alternative interpretation given by Black (1987), which proposes a positive relationship between these two measures based on the impacts of a high-risk technology on the output growth in a business cycle framework. But we can raise other issues to this empirical finding. In fact, following an argument by Varian (1992, p.43), suppose that a firm faces fluctuating prices for its output. Suppose that the firm gets $p 1$ with probability $q$ and $p_{2}$ with probability $(1-q)$. The average price for this firm is $\bar{p}=q p_{1}+(1-q) p_{2}$. Now, let's compare the profits when the price fluctuates to the profits at the average price. Since the profit function is convex, we get

$$
q \pi\left(p_{1}\right)+(1-q) \pi\left(p_{2}\right) \geq \pi\left(q p_{1}+(1-q) p_{2}\right)=\pi(\bar{p})
$$

and thus, fluctuating prices allows profits at least as large as with stabilized and predicted prices. As a consequence, this could induce higher growth. Clearly, this is a simple interpretation and at the end it supposes there is no adjustment costs in investments, but it points out that more research can be done on this issue. It 
is worthwhile to say that in a similar calculation made with US data Grier and Perry (2000) results accepted only Friedman's hypothesis in all the samples they estimated.

An estimation considering a $\operatorname{VAR}(3)$ as identified in the last section also was applied. However, the multivariate SIC pointed out to our model as the best one instead of the $\operatorname{VAR}(3)$ for both CPI and PPI.

Table 4

Bivariate GARCH : CPI and Growth - 1975:3 to 2001:12

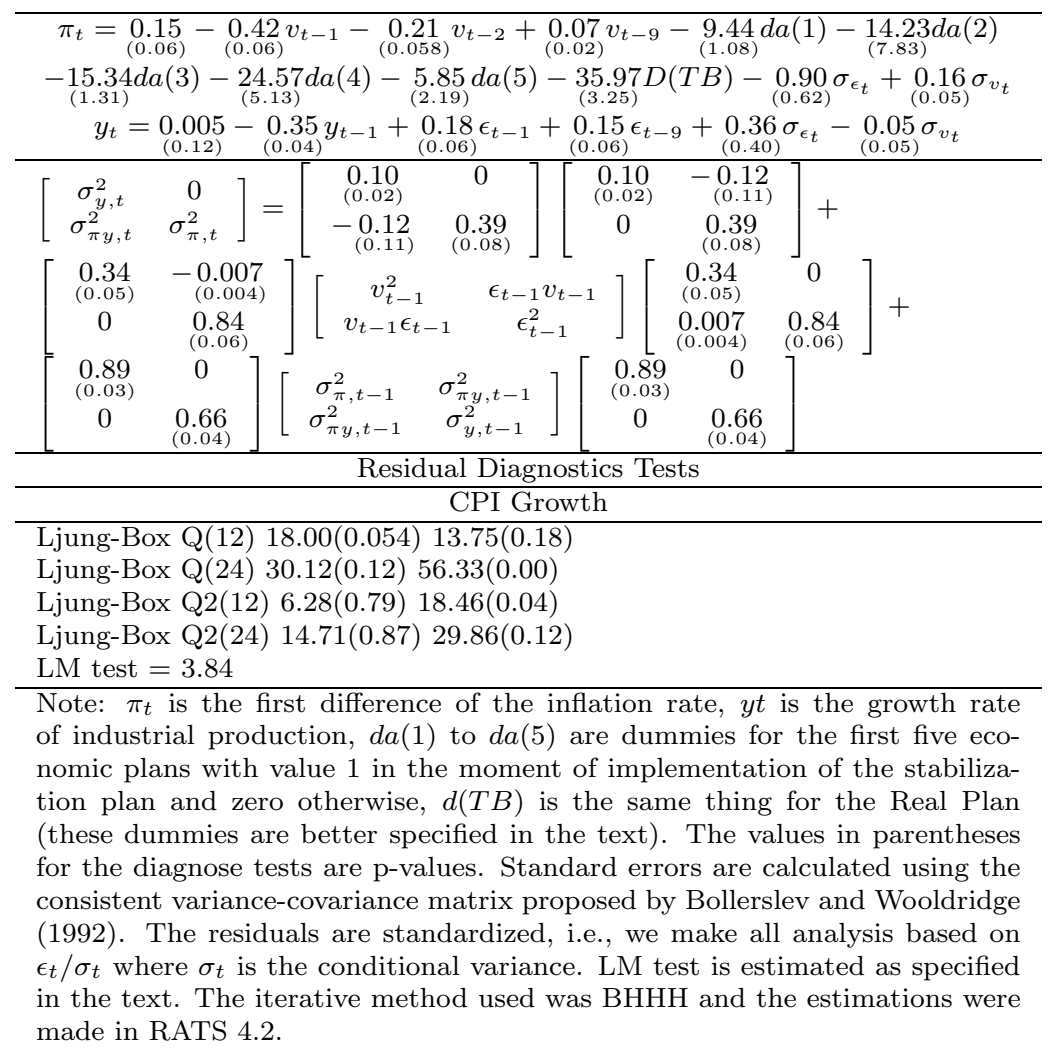


Table 5

Bivariate GARCH : PPI and Growth - 1975:3 to 2001:12

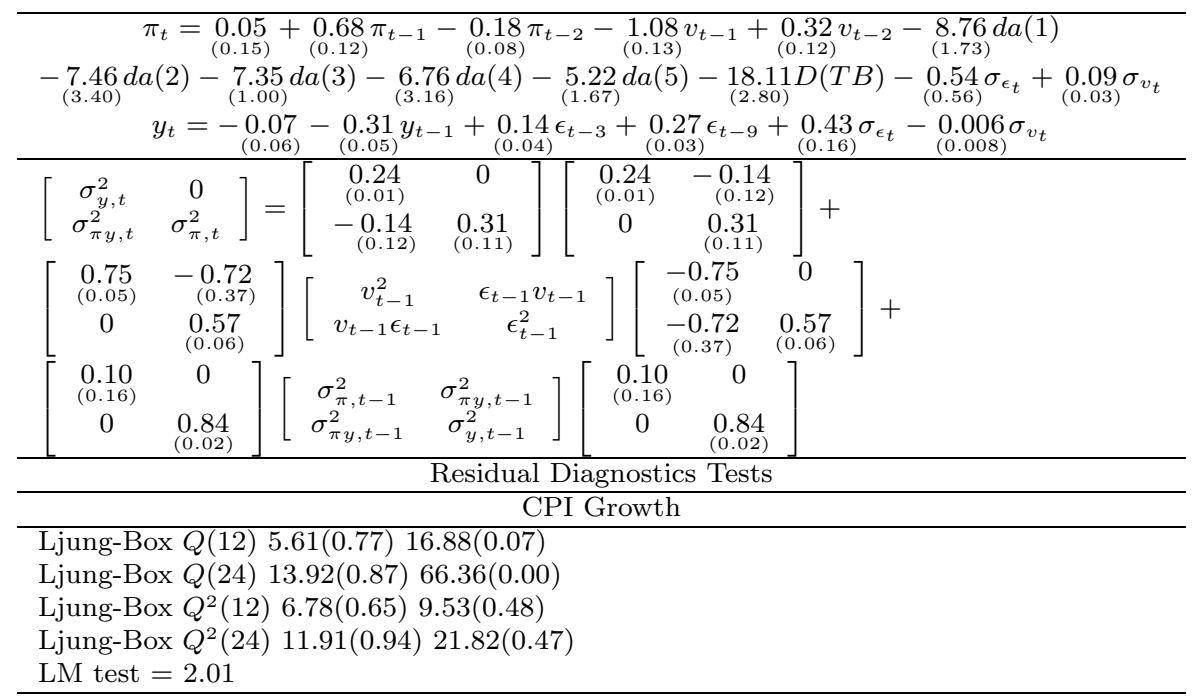

Note: $\pi_{t}$ is the first difference of the inflation rate, $y t$ is the growth rate of industrial production, $d a(1)$ to $d a(5)$ are dummies for the first five economic plans with value 1 in the moment of implementation of the stabilization plan and zero otherwise, $d(T B)$ is the same thing for the Real Plan (these dummies are better specified in the text). The values in parentheses for the diagnose tests are p-values. Standard errors are calculated using the consistent variance-covariance matrix proposed by Bollerslev and Wooldridge (1992). The residuals are standardized, i.e., we make all analysis based on $\epsilon_{t} / \sigma_{t}$ where $\sigma_{t}$ is the conditional variance. LM test is estimated as specified in the text. The iterative method used was $\mathrm{BHHH}$ and the estimations were made in RATS 4.2.

\section{Conclusion}

In the last two decades Brazilian economy went through a huge inflation process and a near economic collapse. The crises brought a lot of uncertainty about the future of the economy and, supposedly, weakened the predictability of the major economic variables. This paper had the objective to find out whether this uncertainty had any impact on two critical economic variables: inflation and growth. In a bivariate Garch-in-Mean estimation I aimed to detect a possible effect of inflation and growth uncertainty on their levels. For this I take four theoretical arguments to base the empirical work. The first hypothesis was based on Cukierman and Meltzer and predicted a positive relationship between uncertainty inflation and inflation. The second one proposed a negative effect between inflation uncertainty and growth and was proposed by Friedman. Devereux's argument showed 
that growth uncertainty should increase inflation and, finally, Ramey and Ramey proposed a negative connection between growth uncertainty and growth. Only Cukierman and Meltzer's hypothesis was accepted for all the estimations.

Some of the other theories were not rejected in the estimations. Indeed, when using CPI as the inflation measure we found a significant negative connection between inflation uncertainty and growth and when using PPI we found a result that contradicts Ramey and Ramey and for which there are few alternative and plausible explanations as far as I know. ${ }^{19}$

Besides new theoretical research we could estimate a Markov switching model where Brazil goes from stability to explosive growth in prices and then back again. But this will be done in another paper. ${ }^{20}$

\section{References}

Ball, L. (1992). Why does high inflation raise inflation uncertainty? Journal of Monetary Economics, 29:371-388.

Barro, R. J. (1996). Inflation and growth. Federal Reserve Bank of St. Louis Review, 78(3):450-467.

Barro, R. J. \& Gordon, D. B. (1983). Rules, discretion and reputation in a model of monetary policy. Journal of Monetary Economics, 12:101-121.

Berndt, E., Hall, B., Hall, R., \& Hausman, J. (1974). Estimation and inference in nonlinear structural models. Annals of Economic and Social Measurement, 3:653-665.

Black, F. (1987). Business Cycle and Equilibrium. Basil Blackwell, New York.

Bollerslev, T., Engle, R., \& Nelson, D. (1994). ARCH models. In Engle, R. F. \& McFaden, D., editors, Handbook of Econometrics.

Bollerslev, T., Engle, R., \& Wooldridge, J. M. (1988). A capital asset pricing model with time varying covariances. Journal of Political Economy, 96:116-131.

\footnotetext{
${ }^{19}$ Black's hypotheses of high risk technology increasing growth does not seem to fit in an economy that was closed in almost the entire period of analysis and Varian's explanation is clearly rough.

${ }^{20}$ See Hamilton and Li (1996) for details.
} 
Bollerslev, T. \& Wooldridge, J. M. (1992). Quasi-maximum likelihood estimation and inference in dynamic models with time varying covariances. Econometric Reviews, 11:143-172.

Bruno, M. \& Easterday, W. (1998). Inflation crises and long run growth. Journal of Monetary Economics, 41:3-26.

Cukierman, A. \& Meltzer, A. H. (1986). A theory of ambiguity, credibility, and inflation under discretion and asymmetric information. Econometrica, 54:10991128.

De Gregorio, J. (1993). Inflation, taxation and long run growth. Journal of Monetary Economics, 31:271-298.

Deveraux, M. (1989). A positive theory of inflation and inflation variance. Economic Inquiry, 27:105-116.

Doornik, J. (1996). Testing vector error autocorrelation and hetereroskedasticity. http://www.nuff.ox.ac.uk/Users/Doornik/papers/vectest.pdf.

Dotsey, M. \& Sarte, P.-D. (2000). Inflation uncertainty and growth in a cash-inadvance economy. Journal of Monetary Economics, 45:631-655.

Engle, R. F. \& Kroner, K. (1995). Multivariate simultaneous GARCH. Econometric Theory, 11:122-150.

Fisher, S. (1993). The role of macroeconomic factors in growth. Journal Of Monetary Economics, 32:485-512.

Friedman, M. (1977). Nobel lecture: Inflation and unemployment. The Journal of Political Economy, 85:451-472.

Grier, K. B. \& Perry, M. J. (2000). The effects of real and nominal uncertainty on inflation and output growth: Some GARCH-M evidence. Journal of Applied Econometrics, 15:45-58.

Hamilton, J. \& Li, G. (1996). Stock market volatility and the business cycle. Journal of Applied Econometrics, 11:573-593.

Hayek, F. A. (1945). The use of knowledge in society. American Economic Review, 35:519-530. 
Issler, J. V., Reis, E. J., Blanco, F., \& L., C. (1998). Renda permanente e poupanca precaucional: Evidencias empiricas para o Brasil no passado recente. Ensaios Economicos da EPGE/FGV 338.

Johansen, S. (1995). Likelihood-Based Inference in Cointegrated Vector Autoregressive Models. Oxford University Press, Oxford.

Jones, L. \& Manuelli, R. (1995). Growth and the effects of inflation. Journal of Economic Dynamic and Control, 19:1405-1428.

Lucas, R. E. (1973). Some international evidence on output-inflation trade-offs. American Economic Review, 63:326-334.

Lutkepohl, H. (1991). Introduction to multiple time series analysis. Berlin: Springer.

Orphanides, A. \& Judson, R. (1996). Inflation, volatility and growth. Finance and Economics Discussion Series. Board of Governors of the Federal Reserve System. 96-19.

Ozcicek, O. \& McMillin, D. (1999). Lag length selection in vector autoregressive models: Symmetric and asymmetric lags. Applied Economics, 31:517-524.

Perron, P. (1989). The great crash, the oil price shock and the unit root hypothesis. Econometrica, 57:1361-1401.

Perron, P., Cati, R. C., \& Garcia, M. G. P. (1999). Unit root in the presence of abrupt governmental interventions with an application to brazilian data. Journal of Applied Econometrics, 14:27-56.

Perron, P. \& Vogelsang, T. (1994). Additional tests for a unit root allowing for a break in the trend function at an unknown time. Working Paper n. 9422, Universite de Montreal.

Pio, C. (2000). The political construction of a market economy: Stabilization and trade liberalization in Brazil (1985-95). http://www.unb.br/ipr/rel/Pio/anpocs2000.htm.

Ramey, G. \& Ramey, V. (1991). Technology commitment and the cost of economic fluctuation. NBER Working Paper, n. 3755.

Sims, C. (1980). Macroeconomics and reality. Econometrica, 48:1-48. 
Varian, H. (1992). Microeconomic Analysis. W. W. Norton \& Company, New York, third edition.

Walsh, C. (1998). Monetary Theory and Policy. The MIT Press. 